\title{
Dietary Intake Quality Is Affected by Knowledge and Dietary Intake Frequency among Pregnant Women in Muntinlupa, Philippines: A Cross-Sectional Study
}

\author{
Tadashi Yamashita ${ }^{1, *(D)}$, Ramon Emilio Daniel Roces ${ }^{2}$, Cecilia Ladines-Llave ${ }^{2}$, Maria Teresa Reyes Tuliao ${ }^{3}$, \\ Mary Wanjira Kamau ${ }^{4}$ (D), Chika Yamada ${ }^{5}$ (D), Yuko Tanaka ${ }^{6}$, Kyoko Shimazawa ${ }^{1}$, Saori Iwamoto ${ }^{1}$ \\ and Hiroya Matsuo ${ }^{7}$
}

1 Faculty of Nursing, Kobe City College of Nursing, 3-4 Gakuennishi-machi, Nishi-ku, Hyogo, Kobe 651-2103, Japan; shimazawa@tr.kobe-ccn.ac.jp (K.S.); iwamoto@kobe-ccn.ac.jp (S.I.)

2 Ospital ng Muntinlupa, Civic Drive, Filinvest Corporate City, Alabang, Muntinlupa 1771, Philippines; redroces@yahoo.com (R.E.D.R.); caladinesllave@gmail.com (C.L.-L.)

3 City Health Office, City Government of Muntinlupa, Centennial Avenue, Tunasan, Muntinlupa 1770, Philippines; materesatuliao63@gmail.com

4 School of Nursing Sciences, University of Nairobi, P.O. Box 19676, Nairobi 00202, Kenya; kwanjira@uonbi.ac.ke

check for updates

Citation: Yamashita, T.; Roces, R.E.D.; Ladines-Llave, C.; Tuliao, M.T.R.; Kamau, M.W.; Yamada, C.; Tanaka, Y.; Shimazawa, K.; Iwamoto, S.; Matsuo, H. Dietary Intake Quality Is Affected by Knowledge and Dietary Intake Frequency among Pregnant Women in Muntinlupa, Philippines: A Cross-Sectional Study. Int. J. Environ. Res. Public Health 2021, 18, 12306. https://doi.org/10.3390/ ijerph182312306

Academic Editors: Stefania Triunfo and Enrico Iurlaro

Received: 25 September 2021 Accepted: 19 November 2021 Published: 23 November 2021

Publisher's Note: MDPI stays neutral with regard to jurisdictional claims in published maps and institutional affiliations.

Copyright: (c) 2021 by the authors. Licensee MDPI, Basel, Switzerland. This article is an open access article distributed under the terms and conditions of the Creative Commons Attribution (CC BY) license (https:// creativecommons.org/licenses/by/ $4.0 /)$.
5 Department of Environmental Coexistence, Center for Southeast Asian Studies, Kyoto University, 46 Shimoadachi-cho, Yoshida Sakyo-ku, Kyoto 606-8501, Japan; chika128@gmail.com

6 Department of School Health Sciences, Institute of Biomedical Sciences, Tokushima University, 2-24 Shinku-racho, Tokushima 770-8501, Japan; yukon-tanaka@tokushima-u.ac.jp

7 Department of Nursing, Osaka Shin-ai College, 6-2-28 Tsurumi, Tsurumi-ku, Osaka 538-0053, Japan; matsuohyroya0711@gmail.com

* Correspondence: tadashi_y_kobe@yahoo.co.jp; Tel.: +81-78-794-8052

\begin{abstract}
Improving the nutrition of pregnant women is essential in reducing maternal and child mortality, which is one of the global nutritional goals of 2025. This study evaluated the factors related to the quality of dietary intake among pregnant women in Muntinlupa, Philippines. We conducted a cross-sectional study of 280 pregnant women at a hospital in Muntinlupa from March 2019 to August 2019 using questionnaires. After the primary aggregation, multivariate logistic regression analysis was used to identify factors associated with the quality of dietary intake in pregnant women. Approximately half of the women $(46.4 \%, n=130)$ had a low dietary diversity during pregnancy. Less than $30 \%$ of the respondents consumed beans, soybean products, and nuts. In the logistic regression analysis, poor maternal knowledge of nutritional sources to prevent anemia (odds ratio (OR) 4.25, $95 \%$ confidence interval (CI) 1.47-12.32, $p=0.01$ ) and less frequent meal consumption (OR 2.15, 95\% CI 1.08-4.29, $p=0.03$ ) were significantly associated with poor dietary diversity. Our findings are crucial because they suggest that increasing the knowledge of pregnant women about good nutrition and ensuring that dietary intake is frequent and adequate through antenatal care can improve the nutrition of pregnant women.
\end{abstract}

Keywords: food diversity; dietary status; pregnant women; knowledge; food frequency

\section{Introduction}

Micronutrient deficiency causes intrauterine fetal stunting, labor disorders, neonatal and childhood health abnormalities, and decreased quality of life of the mother during pregnancy and after childbirth [1-8]. Iron deficiency anemia, one of the most prevalent micronutrient deficiencies, is the most common cause of indirect obstetric death, and women who develop this condition during pregnancy are at risk of excessive bleeding, sepsis, and death during childbirth [9-13]. The World Health Organization aims to reduce anemia and low birth weight by 50\% and 30\%, respectively, by 2025 [14]. Past studies have shown that dietary diversity is significantly associated with nutritional value in the 
Philippines [15], Vietnam, Mali, and Peru [16-18]. This means that improving dietary quality is important to prevent anemia, especially in low- and middle-income countries.

Improvement in health and well-being, including maternal health, is the third sustainable development goal of the United Nations Development Program for the Philippines [19]. According to the results of a national nutrition survey conducted in the Philippines in 2008, $43 \%$ of pregnant women suffer from anemia; therefore, this is a major health problem in the country [20]. In addition, the current nutrition guidelines in the Philippines reflect the results of the 2008 National Nutrition and Health Survey, in which the importance of eating a more diverse diet during pregnancy was emphasized [21]. According to the 2008 results of the National Nutrition Survey, $26.3 \%$ or about one in every four pregnant Filipino women are nutritionally at risk [22]. Currently, the nutritional status of pregnant women is being improved under the Philippine Health and Nutrition Policy [23], although it has not been successful enough to improve the quality of dietary intake of pregnant women.

A joint team of Filipino and Japanese researchers has been implementing the project, "Primary Prevention of Iron Deficiency Anemia During Pregnancy" since 2019, and our study is a part of this project. The researchers of this project comprise Filipino doctors, Japanese doctors, and Japanese health science experts. Through this project, a study on the factors affecting iron intake in pregnant women in the Philippines has been reported [24], and through the current study, we aimed to focus on the quality of dietary intake of pregnant women. Therefore, we investigated the socioeconomic status of pregnant women and their dietary intake during pregnancy and analyzed the factors that affect the quality of their diet. The results of this study contribute to improving the quality of life of pregnant women in the Philippines, which in turn contributes to improving the health of fetuses and pregnant women.

\section{Materials and Methods}

\subsection{Design and Sampling}

A cross-sectional study was conducted in the department that promotes women's health at the Hospital of Muntinlupa. Our targets were residents of different economic levels; therefore, we chose the Hospital of Muntinlupa, which is used by all residents in Muntinlupa. The data were collected between March and August 2019. The city of Muntinlupa consists of nine districts and is located south of Manila and is a highly urbanized city. The city has a total population of 504,509 in 2015. Muntinlupa has a GDP per capita growth of 5.0\% (2017) and is experiencing rapid economic growth. On the other hand, there are a certain number of poor people who live in dangerous areas such as riverbanks and are vulnerable to disasters such as floods and fires.

Muntinlupa City has three government hospitals and eight private hospitals, with one health center in each district of the city. The Hospital of Muntinlupa is one of the government hospitals that provide medical services to low-income earners. The hospital is also one of the largest hospitals in the region, serving more than 1000 births annually. In addition, in the women's health promotion departments of the hospitals, doctors and nurses provide vaccinations, health consultations, and treatment advice as part of preventive healthcare to women living in the community.

\subsection{Sample Size and Sampling Procedure}

The sample size required for this study was estimated by calculating the proportion of a single population, based on the following assumptions: a 33.0\% rate of poor dietary diversity among pregnant women in the Philippines [25], a 95\% confidence interval (CI), and a $5 \%$ acceptable margin of error. The calculated sample size was 240 , and the final sample size was set to 267 to account for the $10 \%$ non-response rate. Using a systematic random sampling method, pregnant women who are eligible for prenatal care were selected from the 900 pregnant women who underwent their first or second prenatal care at the Hospital of Muntinlupa. All pregnant women, regardless of their gestation period were included, and then, pregnant women with serious illness or obstetric complications were 
excluded from the study. Eventually, 280 participants were included in this study. The sampling rate $(K)$ was $N / n=900 / 280=3.2$. We adopted a lottery method to identify the respondents for the first interview, and for the subsequent interviews, every third pregnant woman was selected.

\subsection{Study Population and Sampling}

The study population consisted of pregnant women between the ages of 18 and 45 years who lived around the Hospital of Muntinlupa and visited the hospital for prenatal care. The participants received antenatal care, immediately after which the questionnaires, written in Tagalog (the national language of the Philippines), were administered by a trained Filipino research assistant.

\subsection{Data Quality and Processing}

The questionnaire comprised 38 closed-ended questions that were created and pretested for use in this study. The questions were categorized as follows: sociodemographic characteristics $(n=6)$, food diversity $(n=11)$, current dietary practices $(n=7)$, maternal knowledge of major signs and symptoms of anemia $(n=7)$, and maternal knowledge of food sources that increase blood iron levels $(n=7)$. While food diversity has been assessed to determine the overall diet quality in previous studies [26,27], in this study, it was investigated as a measure of the quality of dietary intake using the 11-item Food Diversity Score Kyoto (FDSK-11) [28-30]. The reason why we used the FDSK-11 was that pregnant women in the Philippines were found to be more likely to respond to FDSK-11 from our preliminary investigation. The FDSK-11 is a screening tool for evaluating dietary quality based on the frequency of food intake of 11 food groups (grains, potatoes, meat, fish and shellfish, eggs, milk and dairy products, vegetables, seaweed, beans and soybean products, nuts, and fruits) over a week during the last six months [28]. The main outcome variable in this study was the FDSK-11 score, ranging between 0 and 11 points. The higher the score, the greater the food diversity, which indicates high quality of the dietary intake of the participants. The mean FDSK-11 score was 8.54 (standard deviation [SD], 1.80). Thus, respondents with a score of less than 9 were classified as having inadequate dietary diversity, while those with a score of 9 or higher were classified as having adequate dietary diversity. Dietary diversity was coded as 1 for those who showed inadequate dietary diversity and 0 for those who exhibited sufficient dietary diversity.

To ensure the reliability of the study, the test-retest method, in which measurements were taken at the beginning and two weeks later, was adopted. We evaluated the test results using Cohen's kappa statistic to measure the agreement between the ratings of the two tests. After comparison, the questionnaire was considered reliable because the kappa values for all questions were above 0.7 , and all the questions were retained. To ensure relevance, the questionnaires were shared, and their contents were discussed with specialists (doctors, nutritionists, nurses, and midwives) in the local health department of Muntinlupa City.

\subsection{Data Analyses}

The data were analyzed using the same method as in the previous study [24]. In this study, participants who did not answer questions about age, pregnancy, and diet were excluded from the analysis. To assess the level of knowledge regarding daily food intake in decreasing anemia incidence during pregnancy, respondents were asked two questions [31]: (1) major signs and symptoms of anemia during pregnancy and (2) food sources that increase blood iron levels in the body during pregnancy. The participant's level of knowledge was calculated by adding the knowledge scores of the seven items related to the symptoms of anemia ("Feels weak," "Looks pale," "Palpitations," "Headaches," "Dizziness," "Tiredness and easily fatigued," and "Swollen legs") and those related to the seven food items that increase blood iron levels in the body during pregnancy ("Liver"; "Red meat, e.g., beef"; "White meat, e.g., chicken and fish"; "Dark-green leafy vegetables"; 
"Whole-grain cereals, e.g., maize and sorghum"; "Legumes, e.g., beans and peas"; and "Eggs"). In the calculation, the correct answer score for each item was set to 1 and the incorrect answer score was set to 0 . Participants with scores above the median and below the median were categorized into the highly knowledgeable group and slightly knowledgeable group, respectively, based on the knowledge of symptoms of anemia and food sources that increase blood iron levels in the body during pregnancy. To test the multicollinearity between the independent variables, we performed collinearity diagnosis and calculated the variance inflation factor for each variable. We then performed bivariate logistic regression analysis to evaluate the unadjusted association between the dependent variable and each independent variable. However, to maintain the reliability of the analysis, the number of independent variables used in the test was limited. Then, significant variables from which $(p<0.01)$ were incorporated into the multivariate logistic regression analysis to identify factors related to dietary diversity among the participants. All the data in this study were analyzed using the Statistical Package for the Social Sciences, version 26.0 (IBM Corp., Armonk, NY, USA).

\section{Results}

Table 1 shows the characteristics of the study participants. In total, 290 women participated, out of whom 10 were excluded because of missing data, and we ultimately analyzed the data of 280 women. The average age of study participants was 28.3 (SD, 6.5) years, and more than half $(64.4 \%, n=177)$ of them were unemployed. A majority $(88.2 \%$, $n=246$ ) of the participants had an above secondary school education. Considering average household monthly income, the number of participants $(59.6 \%, n=159)$ who earned less than 9999 Philippine pesos was higher than those who earned above 10,000 Philippine pesos. Compared with primiparous women, a little more than half of them were multiparous $(59.3 \%, n=166)$. Furthermore, most of the participants were in their third trimester $(78.2 \%$, $n=219)$.

Table 1. Sociodemographic characteristics of the study participants $(n=280)$.

\begin{tabular}{ccc}
\hline Variable & Number & Percentage \\
\hline Age in years & & \\
$<25$ & 85 & 30.3 \\
$25-34$ & 143 & 51.1 \\
$\geq 35$ & 52 & 18.6 \\
\hline Occupation & & \\
Unemployed & 177 & 64.4 \\
Employed & 98 & 35.6 \\
\hline Education & & \\
Primary & 5 & 1.8 \\
Secondary incomplete & 28 & 10.0 \\
Above secondary & 246 & 88.2 \\
\hline Income per month & & \\
<9999 pesos & 159 & 59.6 \\
$>10,000$ pesos & 108 & 40.4 \\
\hline Parity & & \\
Primiparous & 114 & 40.7 \\
Multiparous & 166 & 59.3 \\
\hline Gestation & & \\
First trimester & 19 & 15 \\
Second trimester & 42 & 78.2 \\
Third trimester & 219 &
\end{tabular}

The mean meal consumption frequency of the study participants was 3.94 (SD, 1.04) times, and most $(73.0 \%, n=184)$ of them consumed meals four times or more daily during 
their current pregnancy. Regarding eating out per week, $85.6 \%(n=238)$ ate out $0-4$ times per week. More than half $(64.6 \%, n=181)$ of the participants consumed tea, cocoa, or coffee. Almost all the respondents $(99.3 \%, n=278)$ did not use alcohol in the previous seven days during their current pregnancy. Most of the women consumed processed foods five or more times per week $(84.2 \%, n=235)$, and a majority $(85.6 \%, n=238)$ of them were using iron and folic acid supplementation during their current pregnancy. Most participants $(61.5 \%, n=169)$ avoided certain foods; of them, $30.2 \%$ avoided unhealthy foods. More than half of the women were receiving information about nutrients during the pregnancy $(63.3 \%, n=150)$.

Regarding maternal knowledge, $59.1 \%(n=165)$ and $87.1 \%(n=243)$ of the participants were considered knowledgeable about the signs and symptoms of anemia and food sources that increase blood iron levels, respectively. The mean FDSK-11 score of the study participants was 8.54 (SD, 1.80). About half $(46.4 \%)$ of the participants had low FDSK-11 scores (Table 2).

Table 2. Dietary practice and maternal knowledge on nutrients in pregnant women $(n=280)$.

\begin{tabular}{|c|c|c|}
\hline Variable & Number & Percentage \\
\hline \multicolumn{3}{|l|}{ Meal frequency per day } \\
\hline $1-3$ times & 68 & 27.0 \\
\hline$\geq 4$ times & 184 & 73.0 \\
\hline \multicolumn{3}{|l|}{ Eating out per week } \\
\hline $0-4$ times & 238 & 85.6 \\
\hline$\geq 5$ times & 40 & 14.4 \\
\hline \multicolumn{3}{|l|}{ Tea, cocoa, or coffee use } \\
\hline No & 99 & 35.4 \\
\hline Yes & 181 & 64.6 \\
\hline \multicolumn{3}{|l|}{ Alcohol use in the previous 7 days } \\
\hline No & 278 & 99.3 \\
\hline Yes & 2 & 0.7 \\
\hline \multicolumn{3}{|l|}{ Processed food eaten per week } \\
\hline$\geq 5$ times & 235 & 84.2 \\
\hline$\overline{0}-4$ times & 44 & 15.8 \\
\hline \multicolumn{3}{|l|}{ Taking IFAS during the current pregnancy } \\
\hline No & 40 & 14.4 \\
\hline Yes & 238 & 85.6 \\
\hline \multicolumn{3}{|l|}{ Avoidance of any food or diet in the current pregnancy } \\
\hline Yes & 169 & 61.5 \\
\hline No & 106 & 38.5 \\
\hline \multicolumn{3}{|l|}{ Reasons for avoiding } \\
\hline To avoid unhealthy food (fatty, salty, sweet, alcohol, caffeine) & 35 & 30.2 \\
\hline Culture & 7 & 6.0 \\
\hline To be a healthy mother & 34 & 29.3 \\
\hline To deliver a healthy baby & 33 & 28.5 \\
\hline Other (dislike, discomfort) & 7 & 6.0 \\
\hline \multicolumn{3}{|l|}{ Information on nutrients during pregnancy } \\
\hline No & 87 & 36.7 \\
\hline Yes & 150 & 63.3 \\
\hline \multicolumn{3}{|l|}{ Maternal knowledge of signs and symptoms of anemia } \\
\hline Slightly knowledgeable & 114 & 40.9 \\
\hline Highly knowledgeable & 165 & 59.1 \\
\hline
\end{tabular}


Table 2. Cont.

\begin{tabular}{ccc}
\hline Variable & Number & Percentage \\
\hline $\begin{array}{c}\text { Maternal knowledge of food sources that } \\
\text { increase the blood iron levels } \\
\text { Slightly knowledgeable } \\
\text { Highly knowledgeable }\end{array}$ & 36 & \\
\hline FDSK-11 & 243 & 12.9 \\
Higher & & \\
Lower & 150 & 53.1 \\
\hline
\end{tabular}

IFAS, iron and folic acid supplementation; FDSK-11, 11-item Food Diversity Score Kyoto.

Figure 1 demonstrates the proportion of nutrients, by food group, consumed by the participants. In the week prior to the survey, $225(80.4 \%)$ participants had consumed grain and $224(80.0 \%)$ had consumed fruit. Furthermore, $213(76.9 \%)$ reported the consumption of vegetables and mushrooms, and 201 respondents (72.3\%) reported the consumption of dairy products including milk, cheese, and yogurt. Additionally, 170 (60.7\%) participants consumed meat, and more than half $(58.3 \%)$ of the respondents reported consuming eggs.

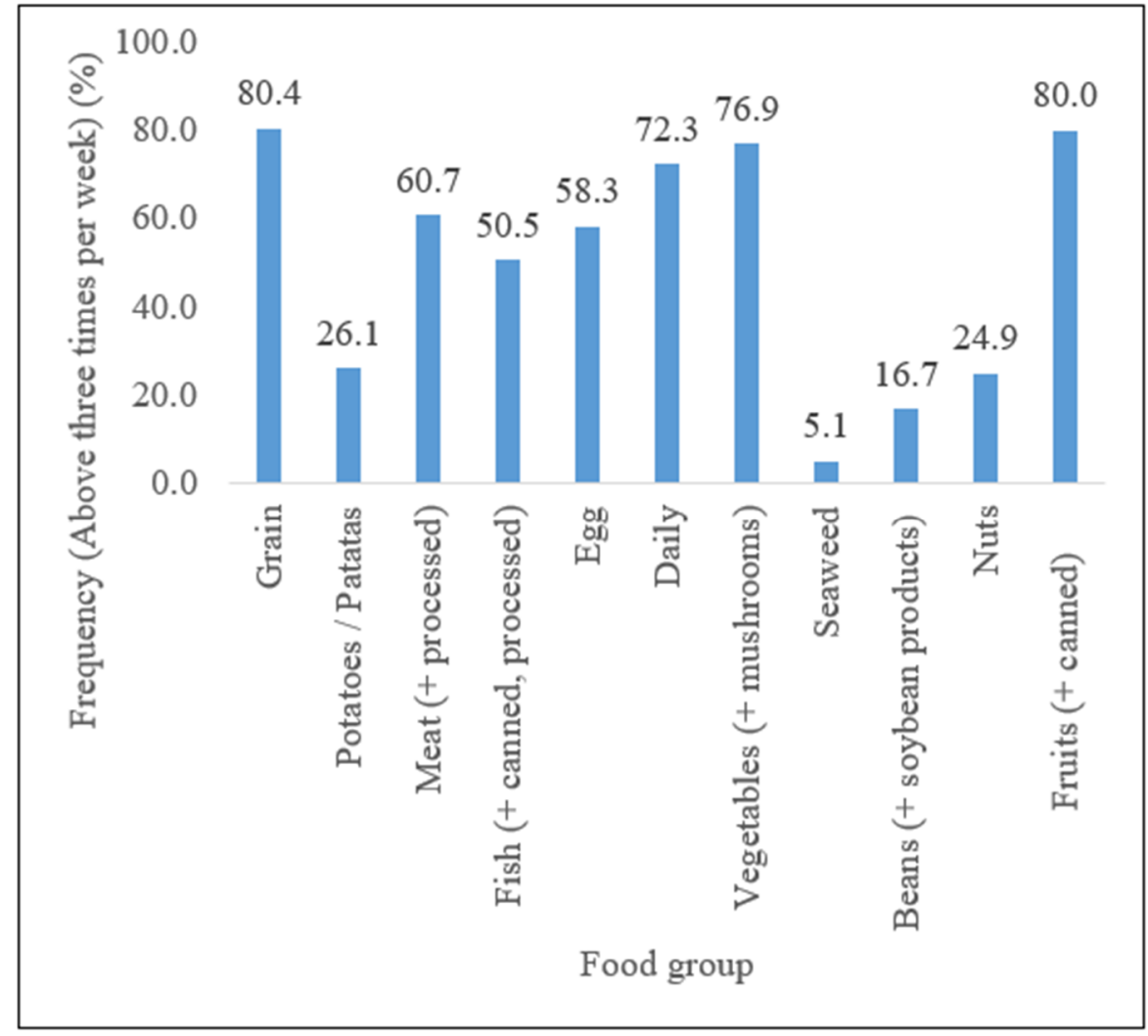

Figure 1. Food groups consumed by the participants over a week in the previous six months.

Approximately half (50.5\%) of the respondents reported consuming fish, including canned and processed fish. Less than a third of the respondents consumed potatoes / patatas, nuts, beans (plus soybean products), and seaweed $(26.1 \%, 24.9 \%, 16.7 \%$, and $5.1 \%$, respectively).

In the logistic regression analysis, poor maternal knowledge of food sources that increase blood iron levels (odds ratio (OR), 4.25; 95\% CI, 1.47-12.32; $p=0.01$ ) and less frequent consumption of meals (OR, 2.15; 95\% CI, 1.08-4.29; $p=0.03$ ) were significantly associated with poor dietary diversity (Table 3 ). 
Table 3. Multivariable regression analyses of dietary diversity among the participants $(n=280)$.

\begin{tabular}{|c|c|c|c|c|c|c|c|c|}
\hline \multirow{3}{*}{ Variables } & \multicolumn{2}{|c|}{ FDSK-11 } & \multirow{2}{*}{\multicolumn{3}{|c|}{ Univariable Analysis }} & \multirow{2}{*}{\multicolumn{3}{|c|}{ Multivariable Analysis }} \\
\hline & \multirow[t]{2}{*}{ High } & \multirow[t]{2}{*}{ Low } & & & & & & \\
\hline & & & OR & $95 \%$ CI & $p$ & OR & $95 \%$ CI & $p$ \\
\hline \multicolumn{9}{|l|}{ Age in years } \\
\hline$<24$ & 43 & 42 & 1 & & & 1 & & \\
\hline $25-34$ & 84 & 59 & 0.72 & $0.42-1.23$ & 0.23 & 0.75 & $0.37-1.51$ & 0.41 \\
\hline$\geq 35$ & 23 & 29 & 1.29 & $0.65-2.58$ & 0.47 & 1.92 & $0.78-4.75$ & 0.16 \\
\hline \multicolumn{9}{|l|}{ Occupation } \\
\hline Unemployed & 90 & 87 & 1.40 & $0.85-2.31$ & 0.18 & 1.25 & $0.65-2.40$ & 0.50 \\
\hline Employed & 58 & 40 & 1 & & & 1 & & \\
\hline \multicolumn{9}{|l|}{ Income per month } \\
\hline$<9999$ pesos & 78 & 81 & 1.63 & $0.99-2.68$ & 0.05 & 1.39 & $0.76-2.54$ & 0.28 \\
\hline$\geq 10,000$ pesos & 66 & 42 & 1 & & & 1 & & \\
\hline \multicolumn{9}{|l|}{ Parity } \\
\hline Primiparous & 58 & 56 & 1.20 & $0.74-1.94$ & 0.45 & 1.44 & $0.77-2.69$ & 0.25 \\
\hline Multiparous & 92 & 74 & 1 & & & 1 & & \\
\hline \multicolumn{9}{|c|}{ Information on nutrients during pregnancy } \\
\hline No & 45 & 42 & 1.19 & $0.70-2.02$ & 0.52 & 0.94 & $0.50-1.77$ & 0.85 \\
\hline Yes & 84 & 66 & 1 & & & 1 & & \\
\hline \multicolumn{9}{|c|}{$\begin{array}{l}\text { Maternal knowledge of signs and } \\
\text { symptoms of anemia }\end{array}$} \\
\hline Slightly knowledgeable & 78 & 73 & 1.187 & $0.74-1.92$ & 0.482 & 1.04 & $0.56-1.91$ & 0.91 \\
\hline Highly knowledgeable & 71 & 57 & 1 & & & 1 & & \\
\hline \multicolumn{9}{|c|}{$\begin{array}{l}\text { Maternal knowledge of food sources that } \\
\text { increase blood iron levels }\end{array}$} \\
\hline Slightly knowledgeable & 68 & 78 & 2.249 & $1.09-4.65$ & $0.029 *$ & 4.25 & $1.47-12.32$ & 0.01 * \\
\hline Highly knowledgeable & 81 & 52 & 1 & & & 1 & & \\
\hline \multicolumn{9}{|l|}{ Meal frequency per day } \\
\hline $1-3$ times & 30 & 39 & 1.76 & $1.01-3.06$ & $0.045 *$ & 2.15 & $1.08-4.29$ & 0.03 * \\
\hline$\geq 4$ times & 119 & 91 & 1 & & & 1 & & \\
\hline \multicolumn{9}{|l|}{ Eating out per week } \\
\hline 0-4 times & 131 & 107 & 1 & & & 1 & & \\
\hline$\geq 5$ times & 18 & 22 & 1.50 & $0.76-2.93$ & 0.241 & 1.899 & $0.78-4.65$ & 0.16 \\
\hline
\end{tabular}

Significant association at 95\% CI, * Significant at $p<0.05$; FDSK-11, 11-item Food Diversity Score Kyoto; CI, confidence interval; OR, odds ratio.

\section{Discussion}

This study analyzed factors associated with dietary diversity and sought to assess the quality of dietary intake of pregnant women in the Philippines from the results. The main findings of this study were as follows: (1) half of the women had a low dietary diversity during pregnancy; (2) more than half of the women avoided certain foods during pregnancy, mainly because they wanted to avoid unhealthy foods; (3) less than $30 \%$ of the respondents consumed beans; and (4) maternal knowledge of nutritional sources as well as frequent meal consumption during pregnancy were significantly associated with dietary diversity.

It has been previously reported that more than $50 \%$ of the pregnant women in the Philippines do not get sufficient nutrition [15]. Another study conducted in Ethiopia reported that high dietary diversity was prevalent in $45 \%$ of pregnant women [32]. In the current study, $46.4 \%$ of the participants had a low dietary diversity score, which is similar to the findings of the abovementioned studies. However, our findings showed a lower score than the minimum dietary diversity score of 57.9\% reported from Indonesia [33]. From the above, it was found that pregnant women in the Philippines cannot eat nutritious 
meals throughout their pregnancy. This may be due to the lack of nutritional knowledge of pregnant women as shown in this study.

Regarding food avoidance, many (61.5\%) of the participants in this study avoided at least one food during their current pregnancy. The major causes for avoiding certain foods were not because of taste or cultural reasons but to avoid unhealthy eating, to be a healthy mother, and to give birth to a healthy baby. The prevalence of food avoidance among the pregnant women in this study is in agreement with that reported in a study in northeastern Ethiopia [34]; however, another study in other parts of Ethiopia reported that only $27.3 \%$ of pregnant women avoided some foods during pregnancy [35]. This discrepancy might have been a result of cultural, social, economic, and environmental determinants of healthy dietary choices during pregnancy.

In the current study, most of the participants consumed grains and fruits. Furthermore, most of the women consumed vegetables, but only one-quarter of them consumed potatoes, which is a starchy vegetable. Over half of the women consumed animal products, but less than one-third of the women had a diet of beans. This finding is consistent with the findings of other studies conducted in the Philippines. It has been reported that cereals, mainly white rice, constitute half of the daily food intake of Filipino adults and the vegetable protein intake is inadequate [36]. Another study also demonstrated that a low intake of vegetables, fruits, and dairy is common because of the rice-dominant diet with few nutrient-dense foods in the Philippines [37-39]. The results of this study showed that animal protein intake during pregnancy was inadequate, and that vegetable protein intake was very inadequate. Inadequate protein intake can lead to anemia in pregnant women. Hence, reduced vegetable protein intake leads to poor dietary diversity, which increases the risk of anemia. However, anemia does not always occur because it is affected by various individual factors.

This study showed that the knowledge of nutritional sources to prevent anemia was significantly associated with a variety of dietary intakes. This meant that pregnant women who were knowledgeable about food sources tended to consume a higher quality diet. This finding is consistent with that reported in an Ethiopian study which showed that dietary knowledge is significantly associated with the quality of dietary practices [40]. A study in the United States also demonstrated that knowledge regarding diet among pregnant women is a predictor of dietary habits [41]. Thus, women with good dietary knowledge tend to think more about good eating habits, which can help in maintaining a nutritious, balanced, and quality diet. Further, an adequate understanding regarding a balanced diet leads to optimal health not only during pregnancy but throughout a woman's life.

The study further showed that pregnant women who consume four or more meals a day are more likely to eat a wider variety of meals, which indicates that dietary frequency is significantly associated with dietary diversity. This finding is similar to that of a study in Ethiopia [42]. It is important to understand that increasing the number of meals during pregnancy leads to a balanced diet and thus to a quality diet. There are reports that education level is important for dietary diversity during pregnancy [43]. In addition, the Filipinos are traditionally influenced by the Spanish food culture and eat one light meal between breakfast and lunch, and another between lunch and dinner. In the Philippines, the term merienda is used to refer to these light meals. Our results suggested that merienda not only increases the number of meals consumed but also provides an opportunity to eat fruits, meats, and vegetables instead of snacks such as sweets. Thus, it is considered that this habit allows the consumption of various foods, which reduces poor dietary diversity. This might be explained by the fact that increased meal intake increases the chance of consuming different types of food.

Our study has some limitations. First, this research was only conducted in a medical facility, and our findings may not apply to the general public. Second, the estimations of dietary diversity practice in this study may be inaccurate due to recall bias and self-reporting. Third, it was not possible to analyze each gestation period because the majority of pregnant women were in their third trimester of pregnancy. Finally, while other studies included 
factors considered to be related to dietary diversity, such as livestock ownership [44], participation in food shopping [45], and husband support [46,47], they were not examined in this study.

\section{Conclusions}

Nutritional insecurity and associated health problems remain important public health issues, primarily in low- and middle-income countries, such as the Philippines. This study showed that the quality of dietary intake in half of the Filipino women was low during pregnancy. In addition, lack of knowledge about nutritious food sources and reduced dietary intake were associated with low dietary quality. Thus, it is important to improve the quality of dietary intake during pregnancy and increase knowledge regarding healthy dietary sources for the prevention of anemia. Educating women only during their pregnancy is not enough to increase their knowledge on proper nutrition and diet. It may be important for women to be educated about the importance of diet from an early age. In addition to improving the knowledge of pregnant women, it is recommended to enhance dietary guidance during prenatal health examinations in order to improve dietary diversity during pregnancy.

Author Contributions: Conceptualization, T.Y., R.E.D.R., C.L.-L., M.T.R.T. and H.M.; methodology, T.Y. and C.Y.; software, C.Y.; validation, C.Y., Y.T. and H.M.; formal analysis, T.Y., M.W.K. and C.Y.; investigation, T.Y., R.E.D.R. and C.L.-L.; resources, C.Y.; data curation, C.Y.; writing-original draft preparation, T.Y., M.W.K. and H.M.; writing-review and editing, T.Y., M.T.R.T. and M.W.K.; visualization, T.Y.; supervision, K.S., S.I., M.T.R.T., M.W.K. and H.M.; project administration, T.Y., R.E.D.R., C.L.-L. and M.T.R.T.; funding acquisition, T.Y. All authors have read and agreed to the published version of the manuscript.

Funding: This work was supported by JSPS KAKENHI Grant Number JP19K11277.

Institutional Review Board Statement: The study was conducted according to the guidelines of the Declaration of Helsinki and approved by two institutions, the Research Administration of the Hospital of Muntinlupa (No. 2019-02), dated 9 May 2019, and the Kobe City College of Nursing Ethics Research Committee (No. 18112-05), dated 24 May 2019.

Informed Consent Statement: Participation in this study was voluntary, and the study participants provided oral and written informed consent before the interview. The participants were told that they could withdraw from the study at any time. They were informed of the purpose of the study, assured of information confidentiality, and given the choice to decide not to answer offensive or painful questions.

Data Availability Statement: The data presented in this study are available on request from the corresponding author.

Acknowledgments: We would like to thank all the research participants for their understanding and motivation. We would also like to express gratitude for the support provided by the teams from the Sentrong Aruga para sa Kababaihan and the Ospital ng Muntinlupa. We would also like to thank the Japan Society for the Promotion of Science KAKENHI for supporting this research.

Conflicts of Interest: The authors declare no conflict of interest.

\section{References}

1. World Health Organization. The Nutrition Challenge. Available online: https://apps.who.int/iris/bitstream/handle/10665/27 7440/WHO-NMH-NHD-18.10-eng.pdf (accessed on 25 September 2021).

2. Baker, P.N.; Wheeler, S.J.; Sanders, T.A.; Thomas, J.E.; Hutchinson, C.J.; Clarke, K.; Berry, J.L.; Jones, R.L.; Seed, P.T.; Poston, L. A prospective study of micronutrient status in adolescent pregnancy. Am. J. Clin. Nutr. 2009, 89, 1114-1124. [CrossRef]

3. Haider, B.A.; Yakoob, M.Y.; Bhutta, Z.A. Effect of multiple micronutrient supplementation during pregnancy on maternal and birth outcomes. BMC Public Health 2011, 11, S19. [CrossRef] [PubMed]

4. Sharma, R.; Mehta, S. Ascorbic acid concentration and preterm premature rupture of membranes. J. Obstet. Gynaecol. India 2014, 64, 417-420. [CrossRef] [PubMed] 
5. West, K.P.; Shamim, A.A.; Mehra, S.; Labrique, A.B.; Ali, H.; Shaikh, S.; Klemm, R.D.; Wu, L.S.; Mitra, M.; Haque, R.; et al. Effect of maternal multiple micronutrient vs iron-folic acid supplementation on infant mortality and adverse birth outcomes in rural bangladesh: The JiVitA-3 randomized trial. J. Am. Med Assoc. 2014, 312, 2649-2658. [CrossRef]

6. Hart, P.H.; Lucas, R.M.; Walsh, J.P.; Zosky, G.R.; Whitehouse, A.J.; Zhu, K.; Allen, K.L.; Kusel, M.M.; Anderson, D.; Mountain, J.A.; et al. Vitamin D in fetal development: Findings from a birth cohort study. Pediatrics 2015, 135, e167-e173. [CrossRef]

7. Jans, G.; Matthys, C.; Bogaerts, A.; Lannoo, M.; Verhaeghe, J.; Van der Schueren, B.; Devlieger, R. Maternal micronutrient deficiencies and related adverse neonatal outcomes after bariatric surgery: A systematic review. Adv. Nutr. 2015, 6, 420-429. [CrossRef]

8. Gernand, A.D.; Schulze, K.J.; Stewart, C.P.; West, K.P.; Christian, P. Micronutrient deficiencies in pregnancy worldwide: Health effects and prevention. Nat. Rev. Endocrinol. 2016, 12, 274-289. [CrossRef]

9. Black, R.E.; Allen, L.H.; Bhutta, Z.A.; Caulfield, L.E.; de Onis, M.; Ezzati, M.; Mathers, C.; Rivera, J. Maternal and child undernutrition: Global and regional exposures and health consequences. Lancet 2008, 371, 243-260. [CrossRef]

10. Charles, A.M.; Campbell-Stennett, D.; Yatich, N.; Jolly, P.E. Predictors of anemia among pregnant women in Westmoreland, Jamaica. Health Care Women Int. 2010, 31, 585-598. [CrossRef] [PubMed]

11. Lumbiganon, P.; Laopaiboon, M.; Intarut, N.; Vogel, J.P.; Souza, J.P.; Gülmezoglu, A.M.; Mori, R.; WHO Multicountry Survey on Maternal and Newborn Health Research Network. Indirect Causes of Severe Adverse Maternal Outcomes: A Secondary Analysis of the WHO Multicountry Survey on Maternal and Newborn Health. Int. J. Obstet. Gynaecol. 2014, 121, 32-39. [CrossRef] [PubMed]

12. Souza, J.P. The World Health Organization multicountry survey on maternal and newborn health project at a glance: The power of collaboration. Int. J. Obstet. Gynaecol. 2014, 121, 5-8. [CrossRef]

13. World Health Organization. Global Nutrition Monitoring Framework. Available online: https://apps.who.int/iris/rest/ bitstreams / 1093537 / retrieve (accessed on 25 September 2021).

14. World Health Organization. Women's Health. Available online: https://www.who.int/health-topics/women-s-health/ (accessed on 16 September 2021).

15. Arimond, M.; Wiesmann, D.; Becquey, E.; Carriquiry, A.; Daniels, M.C.; Deitchler, M.; Fanou-Fogny, N.; Joseph, M.L.; Kennedy, G.; Martin-Prevel, Y.; et al. Simple food group diversity indicators predict micronutrient adequacy of women's diets in 5 diverse, resource-poor settings. J. Nutr. 2010, 140, 2059S-2069S. [CrossRef] [PubMed]

16. Ogle, B.M.; Hung, P.H.; Tuyet, H.T. Significance of wild vegetables in micronutrient intakes of women in Vietnam: An analysis of food variety. Asia Pac. J. Clin. Nutr. 2001, 10, 21-30. [CrossRef] [PubMed]

17. Hatløy, A.; Torheim, L.E.; Oshaug, A. Food variety-A good indicator of nutritional adequacy of the diet? A case study from an urban area in Mali, West Africa. Eur. J. Clin. Nutr. 1998, 52, 891-898. [CrossRef]

18. Marquis, G.S.; Habicht, J.P.; Lanata, C.F.; Black, R.E.; Rasmussen, K.M. Breast milk or animal-product foods improve linear growth of Peruvian toddlers consuming marginal diets. Am. J. Clin. Nutr. 1997, 66, 1102-1109. [CrossRef]

19. United Nations Development Programme. Goal 3: Good Health and Well-Being. Available online: https://www1.undp.org/ content/oslo-governance-centre/en/home/sustainable-development-goals/goal-3-good-health-and-well-being.html (accessed on 16 September 2021).

20. Department of Science and Technology. Nutritional Guidelines for Filipinos: A Prescription to Good Nutrition. Available online: https: / / region4a.dost.gov.ph/ (accessed on 25 September 2021).

21. Food and Nutrition Research Institute. 7th National Nutrition Survey: 2008 Anthropometric Survey Component. Available online: https:/ / www.fnri.dost.gov.ph/images/sources/anthrop_preschool_adoles.pdf (accessed on 16 September 2021).

22. Food and Nutrition Research Institute. 7th National Nutrition Survey: 2008 Food Consumption Survey Component. Available online: http:/ /www.fnri.dost.gov.ph/images/sources/food_consumption_individual.pdf (accessed on 16 September 2021).

23. Republic of the Philippines, Department of Health, National Nutrition Council. Philippine Plan of Action for Nutrition 2017-2022. Available online: https:/ / www.nnc.gov.ph/phocadownloadpap/PPAN/18Sept_PPAN2017_2022Executive\%20Summary.pdf (accessed on 16 September 2021).

24. Yamashita, T.; Roces, R.E.D.; Ladines-Llave, C.; Reyes Tuliao, M.T.; Wanjira Kamau, M.; Yamada, C.; Tanaka, Y.; Shimazawa, K.; Iwamoto, S.; Matsuo, H. Maternal knowledge associated with the prevalence of iron and folic acid supplementation among pregnant women in Muntinlupa, Philippines: A cross-sectional study. Patient Prefer. Adherence 2021, 15, 501-510. [CrossRef] [PubMed]

25. Abris, G.P.; Kim, N.H.; Provido, S.M.P.; Hong, S.; Yu, S.H.; Lee, C.B.; Lee, J.E. Dietary diversity and nutritional adequacy among married Filipino immigrant women: The Filipino Women's Diet and Health Study (FiLWHEL). BMC Public Health 2018, 18, 359. [CrossRef] [PubMed]

26. Torheim, L.E.; Barikmo, I.; Parr, C.L.; Hatløy, A.; Ouattara, F.; Oshaug, A. Validation of food variety as an indicator of diet quality assessed with a food frequency questionnaire for Western Mali. Eur. J. Clin. Nutr. 2003, 57, 1283-1291. [CrossRef]

27. Savy, M.; Martin-Prével, Y.; Sawadogo, P.; Kameli, Y.; Delpeuch, F. Use of variety/diversity scores for diet quality measurement: Relation with nutritional status of women in a rural area in Burkina Faso. Eur. J. Clin. Nutr. 2005, 59, 703-716. [CrossRef] 
28. Kimura, Y.; Okumiya, K.; Sakamoto, R.; Ishine, M.; Wada, T.; Kosaka, Y.; Wada, C.; Ishimoto, Y.; Hirosaki, M.; Kasahara, Y.; et al. Comprehensive geriatric assessment of elderly highlanders in Qinghai, China IV: Comparison of food diversity and its relation to health of Han and Tibetan elderly. Geriatr. Gerontol. Int. 2009, 9, 359-365. [CrossRef] [PubMed]

29. Kimura, Y.; Wada, T.; Ishine, M.; Ishimoto, Y.; Kasahara, Y.; Konno, A.; Nakatsuka, M.; Sakamoto, R.; Okumiya, K.; Fujisawa, M.; et al. Food diversity is closely associated with activities of daily living, depression, and quality of life in community-dwelling elderly people. J. Am. Geriatr. Soc. 2009, 57, 922-924. [CrossRef]

30. Kimura, Y.; Wada, T.; Okumiya, K.; Ishimoto, Y.; Fukutomi, E.; Kasahara, Y.; Chen, W.; Sakamoto, R.; Fujisawa, M.; Otsuka, K.; et al. Eating Alone Among Community-dwelling Japanese elderly: Association with depression and food diversity. J. Nutr. Health Aging 2012, 16, 728-731. [CrossRef]

31. Kamau, M.W.; Mirie, W.; Kimani, S.T. Maternal knowledge on iron and folic acid supplementation and associated factors among pregnant women in a rural county in Kenya. Int. J. Afr. Nurs. Sci. 2019, 10, 74-80. [CrossRef]

32. Yeneabat, T.; Adugna, H.; Asmamaw, T.; Wubetu, M.; Admas, M.; Hailu, G.; Bedaso, A.; Amare, T. Maternal dietary diversity and micronutrient adequacy during pregnancy and related factors in East Gojjam Zone, Northwest Ethiopia, 2016. BMC Pregnancy Childbirth 2019, 19, 173. [CrossRef]

33. Diana, R.; Khomsan, A.; Anwar, F.; Christianti, D.F.; Kusuma, R.; Rachmayanti, R.D. Dietary quantity and diversity among anemic pregnant women in Madura Island, Indonesia. J. Nutr. Metab. 2019, 2647230. [CrossRef] [PubMed]

34. Diddana, T.Z. Factors associated with dietary practice and nutritional status of pregnant women in Dessie Town, Northeastern Ethiopia: A community-based cross-sectional study. BMC Pregnancy Childbirth 2019, 19, 517. [CrossRef]

35. Zelalem, A.; Endeshaw, M.; Ayenew, M.; Shiferaw, S.; Yirgu, R. Effect of nutrition education on pregnancy specific nutrition knowledge and healthy dietary practice among pregnant women in Addis Ababa. Clin. Mother Child Health 2017, 14, 1000265. [CrossRef]

36. Rutherfurd, S.M.; Fanning, A.C.; Miller, B.J.; Moughan, P.J. Protein digestibility-corrected amino acid scores and digestible indispensable amino acid scores differentially describe protein quality in growing male Rats. J. Nutr. 2015, 145, 372-379. [CrossRef]

37. Savoca, M.R.; Arcury, T.A.; Leng, X.; Bell, R.A.; Chen, H.; Anderson, A.; Kohrman, T.; Quandt, S.A. The diet quality of rural older adults in the South as measured by Healthy Eating Index-2005 varies by ethnicity. J. Am. Diet. Assoc. 2009, 109, $2063-2067$. [CrossRef] [PubMed]

38. Angeles-Agdeppa, I.; Sun, Y.; Denney, L.; Tanda, K.V.; Octavio, R.A.D.; Carriquiry, A.; Capanzana, M.V. Food sources, energy and nutrient intakes of adults: 2013 Philippines National Nutrition Survey. Nutr. J. 2019, 18, 59. [CrossRef]

39. Angeles-Agdeppa, I.; Sun, Y.; Tanda, K.V. Dietary pattern and nutrient intakes in association with non-communicable disease risk factors among Filipino adults: A cross-sectional study. Nutr. J. 2020, 19, 79. [CrossRef] [PubMed]

40. Nana, A.; Zema, T. Dietary practices and associated factors during pregnancy in northwestern ethiopia. BMC Pregnancy Childbirth 2018, 18, 183. [CrossRef] [PubMed]

41. Fouda, L.; Ahmed, M.; Shehab, N.S. Nutritional awareness of women during pregnancy. J. Am. Sci. $2012,8,494-502$.

42. Jemal, K.; Awol, M. Minimum dietary diversity score and associated factors among pregnant women at Alamata General Hospital, Raya Azebo Zone, Tigray Region, Ethiopia. J. Nutr. Metab. 2019, 2019, 8314359. [CrossRef] [PubMed]

43. Desta, M.; Akibu, M.; Tadese, M.; Tesfaye, M. Dietary diversity and associated factors among pregnant women attending antenatal clinic in Shashemane, Oromia, Central Ethiopia: A cross-sectional study. J. Nutr. Metab. 2019, 2019, 3916864. [CrossRef]

44. Harris-Fry, H.; Azad, K.; Kuddus, A.; Shaha, S.; Nahar, B.; Hossen, M.; Younes, L.; Costello, A.; Fottrell, E. Socio-economic determinants of household food security and women's dietary diversity in rural Bangladesh: A cross-sectional study. J. Health Popul. Nutr. 2015, 33, 2. [CrossRef] [PubMed]

45. Jilcott Pitts, S.B.; Gustafson, A.; Wu, Q.; Leah Mayo, M.; Ward, R.K.; McGuirt, J.T.; Rafferty, A.P.; Lancaster, M.F.; Evenson, K.R.; Keyserling, T.C.; et al. Farmers' market use is associated with fruit and vegetable consumption in diverse Southern rural communities. Nutr. J. 2014, 13, 1. [CrossRef]

46. Nguyen, P.H.; Sanghvi, T.; Kim, S.S.; Tran, L.M.; Afsana, K.; Mahmud, Z.; Aktar, B.; Menon, P. Factors influencing maternal nutrition practices in a large scale maternal, newborn and child health program in Bangladesh. PLoS ONE 2017, 12, e0179873. [CrossRef]

47. Ochieng, J.; Afari-Sefa, V.; Lukumay, P.J.; Dubois, T. Determinants of dietary diversity and the potential role of men in improving household nutrition in Tanzania. PLoS ONE 2017, 12, e0189022. [CrossRef] 